\title{
T3b Stage Finding
}

National Cancer Institute

\section{Source}

National Cancer Institute. T3b Stage Finding. NCI Thesaurus. Code C48730.

A general term that refers to a TNM finding of a primary tumor usually indicating that the cancer is locally invasive. The definition of T3b TNM finding depends on the specific type of cancer that it refers to; for example, for kidney cancer it refers to a primary tumor that grossly extends into the vena cava below the diaphragm; for cervical cancer it refers to a primary tumor that extends to the pelvic wall and/or causes hydronephrosis or nonfunctioning kidney; for liver cancer it refers to a single tumor or multiple tumors of any size involving a major branch of the portal vein or hepatic vein. 